\title{
A literatura de cordel como metodologia ativa no ensino e aprendizagem de Química
}

\author{
Cordel literature as an active methodology in the teaching and learning of Chemistry \\ La literatura de cordel como metodología activa en la enseñanza y el aprendizaje de la Química
}

\begin{abstract}
Recebido: 05/06/2021 | Revisado: 10/06/2021 | Aceito: 15/06/2021 | Publicado: 19/06/2021
Antonia Carliane Sousa Oliveira ORCID: https://orcid.org/0000-0002-9113-0956 Instituto Federal de Educação, Ciência e Tecnologia do Maranhão, Brasil E-mail: carliane.sousa@acad.ifma.edu.br Joniery Rubim de Souza ORCID: https://orcid.org/0000-0002-0293-2886 Instituto Federal de Educação, Ciência e Tecnologia do Maranhão, Brasil E-mail: joniery@ifma.edu.br Karine da Silva Almeida ORCID: https://orcid.org/0000-0002-9594-106X Instituto Federal de Educação, Ciência e Tecnologia do Maranhão, Brasil E-mail: karine.almeida@acad.ifma.edu.br Bruna Martina Araújo da Silva ORCID: https://orcid.org/0000-0001-8821-7025 Instituto Federal de Educação, Ciência e Tecnologia do Maranhão, Brasil E-mail: bruna.martina@acad.ifma.edu.br Ana Júlia Rego Vieira da Luz ORCID: https://orcid.org/0000-0003-0134-1889 Instituto Federal de Educação, Ciência e Tecnologia do Maranhão, Brasil E-mail: anajulia@ifma.edu.br
\end{abstract}

\begin{abstract}
Resumo
As discussões acerca dos métodos de ensino de química têm estimulado estudos de cunho didático-pedagógico que apontam a necessidade do uso de métodos e estratégias de ensino que possibilitem aos alunos alternativas para dirimir as dificuldades na aprendizagem. Nesse sentindo, a presente pesquisa teve como principal objetivo investigar a eficácia da utilização do gênero literatura de cordel como metodologia ativa no ensino e aprendizagem de química no ensino médio. O estudo caracterizou-se como de natureza básica, de abordagem metodológica quanti-qualitativa, por meio bibliográfico e de campo, e quanto aos seus objetivos é descritivo e exploratório. A população da pesquisa é compreendida de docentes da área de Química e de alunos dos cursos técnicos integrados ao ensino médio do Instituto Federal do Maranhão - IFMA, Campus Caxias. O percentual de amostra foi definido após o levantamento do quantitativo de docentes e de alunos. Quanto a elaboração dos instrumentos de coleta de dados foi utilizado o modelo sugerido por Marconi e Lakatos (2017), seguidos da respectiva aplicação de questionários semiestruturados. No que tange ao tratamento dos dados, utilizou-se o programa Microsoft Excel - versão 2016 para tabulação e geração de gráficos, e posterior análise e discussão dos resultados. Ao final do estudo, constatou-se que o gênero textual literatura de cordel contribuiu de forma significativa para o ensino e aprendizagem de química como ferramenta de incentivo a produção do conhecimento científico.
\end{abstract}

Palavras-chave: Ensino e aprendizagem; Literatura de cordel; Ensino de Química.

\begin{abstract}
Discussions on chemistry teaching methods have stimulated didactic-pedagogical studies that point out the need to use teaching methods and strategies that provide students with alternatives to overcome learning difficulties. Thus, the main objective of this research was to investigate the effectiveness of using the genre of cordel literature as an active methodology in the teaching and learning of chemistry in high school. The study was characterized for being basic, with a quantitative-qualitative methodological approach, through bibliographic and fieldwork, and in terms of its objectives it is descriptive and exploratory. The research population is composed of Chemistry teachers and students of technical courses integrated to the high school of the Federal Institute of Maranhão - IFMA, Caxias Campus. The percentage of the sample was defined after the quantitative survey conducted to teachers and students. Regarding the elaboration of the data collection instruments, the model suggested by Marconi and Lakatos (2017) was used followed by the respective application of semi-structured questionnaires. As for data processing, the Microsoft Excel program version 2016 was used for the tabulation and generation of graphs, and subsequent analysis and discussion of the results. At the end of the study, it was found that the textual genre cordel literature contributed significantly to the teaching and learning of chemistry as a tool to promote the production of scientific knowledge.
\end{abstract}

Keywords: Teaching and learning; Cordel literature; Teaching of Chemistry. 


\begin{abstract}
Resumen
Las discusiones sobre los métodos de enseñanza de la química han estimulado los estudios didáctico-pedagógicos que señalan la necesidad de utilizar métodos y estrategias de enseñanza que proporcionen a los alumnos alternativas para superar las dificultades de aprendizaje. En este sentido, el objetivo principal de esta investigación fue investigar la eficacia de utilizar el género de la literatura de cordel como metodología activa en la enseñanza y aprendizaje de la química en la escuela secundaria. El estudio se caracterizó por ser de carácter básico, con un enfoque metodológico cuanti-cualitativo, mediante trabajo bibliográfico y de campo, y en cuanto a sus objetivos es descriptivo y exploratorio. La población de la investigación está compuesta por profesores del área de química y alumnos de cursos técnicos integrados a la enseñanza média del Instituto Federal de Maranhão - IFMA, Campus de Caxias. El porcentaje de la muestra se definió tras la encuesta cuantitativa realizada a profesores y alumnos. En cuanto a la elaboración de los instrumentos de recolección de datos, se utilizó el modelo sugerido por Marconi y Lakatos (2017), seguido de la respectiva aplicación de cuestionarios semiestructurados. En cuanto al tratamiento de los datos, se utilizó el programa Microsoft Excel - versión 2016 para la tabulación y generación de gráficos, y posterior análisis y discusión de los resultados. Al final del estudio, se constató que el género textual literatura de cordel contribuyó de manera significativa a la enseñanza y el aprendizaje de la química como herramienta para fomentar la producción de conocimiento científico. Palabras clave: Enseñanza y aprendizaje; Literatura de cordel; Enseñanza de la Química.
\end{abstract}

\title{
1. Introdução
}

A leitura é concebida pelo estudo como uma necessidade humana, pois o homem é um ser social e em seu processo de retroações humanas, no contato com seus semelhantes, constrói processos de sociabilidades no mundo em que vive, por meio de linguagens, seus sentidos e significados. Por isso, é necessário valorizar o ensino da leitura no contexto da sala de aula, valorizando a participação com envolvimento do aluno, da família, da sociedade (Andrade, 2012, p.1).

O uso do cordel pode contribuir para despertar e estimular a curiosidade dos sujeitos acerca dos mais diferentes temas de Ciências. Por meio deste é possível que os alunos sejam desafiados a construírem seus próprios cordéis, passando assim de posições passivas na sala de aula para posturas autorais ativas na construção de seu próprio conhecimento. Trata-se de um exercício de criatividade que exige um trabalho de pesquisa e de aprofundamento no tema enfocado (Santos et al., 2019, p. 42).

O ensino de química nos três anos correspondentes ao ensino médio, bem como as demais ciências, não se constitui tarefa fácil. Há um contraste entre o insucesso do professor, que, por vezes, se frustra quando sua estratégia de ensino não tem eficácia, e o desestímulo, ou mesmo fracasso dos alunos, vítimas da utilização de abordagens inadequadas aos conteúdos que requerem, em muitos casos, uma decodificação por parte destes, por meio de fórmulas, memorização e regras desarticuladas (Carreiro et al., 2012).

Vale destacar que o cordel vem ocupando um espaço maior nas aulas, dada a sua estreita ligação com a cultura popular dentro das instituições de ensino, incluindo as universidades. Em consequência disso, ampliam-se as pesquisas em torno dessas produções populares, incluindo, entre essas investigações científicas, alguns estudos que têm como recorte analítico a discussão sobre a importância do cordel como ferramenta auxiliar no processo de ensino-aprendizagem (Lima, 2013, p. 133-134).

Cabe observar, que há necessidade de uma renovação do ensino de Ciências nas escolas, considerando-se que há inúmeras alternativas metodológicas, como a utilização do gênero textual literatura de cordel na sala de aula, neste caso. Nessa perspectiva, a realização deste trabalho, objetivou investigar a eficácia da utilização do gênero literatura de cordel nas aulas de química como uma forma de provocar os alunos, no sentido de estimular sua criatividade, em especial as aulas ministradas ao ensino médio, oportunizando os alunos a vivenciarem outras experiências de aprendizagem na vida estudantil.

\section{Metodologia}

A presente pesquisa possui abordagem metodológica quanti-qualitativa, sendo realizada com base em pesquisa bibliográfica. Dessa forma, preocupa-se tanto com a quantificação dos dados como a objetivação dos fenômenos, suas relações e características. 
A pesquisa bibliográfica, baseia-se em material já elaborado para a consulta, contendo várias fontes de informações, como periódicos (revistas, jornais), livros, catálogos. Conforme Gil (2010, p. 45):

A principal vantagem da pesquisa bibliográfica reside no fato de permitir ao investigador a cobertura de uma gama de fenômenos muito mais ampla do que aquela que poderia pesquisar diretamente. Essa vantagem torna-se particularmente importante quando o problema de pesquisa requer dados muito dispersos pelo espaço.

Além desse procedimento metodológico, a pesquisa também contempla o estudo de campo, o qual possibilita ao pesquisador o contato com o objeto em seu ambiente próprio. Como relata Severino (2017, p. 90):

Na pesquisa de campo, o objeto/fonte é abordado em seu meio ambiente próprio. A coleta dos dados é feita nas condições naturais em que os fenômenos ocorrem, sendo assim diretamente observados, sem intervenção e manuseio por parte do pesquisador.

No que se refere aos objetivos, classifica-se como descritiva e exploratória. Ambas requerem informações sobre o objeto de pesquisa, sendo, portanto, necessárias para caracterizar e familiarizar-se com as questões investigadas. Prodanov (2013, p. 5152) salienta os dois tipos de pesquisas, respectivamente:

A pesquisa descritiva visa a descrever as características de determinada população ou fenômeno ou o estabelecimento de relações entre variáveis [...] quando a pesquisa se encontra na fase preliminar, tem como finalidade proporcionar mais informações sobre o assunto que vamos investigar, possibilitando sua definição e seu delineamento.

Portanto, a pesquisa exploratória é mais flexível e apresenta mais possibilidades de estudo acerca do tema adotado. Enquanto a descritiva explora as características do objeto estudado ou dos fenômenos ocorridos sem que haja interferência do pesquisador.

Inicialmente foi realizada uma revisão das fontes bibliográficas, visando coletar informações sobre a temática de estudo. Para tal, foram utilizadas as ferramentas do portal de periódicos CAPES, e da base de dados do Google Acadêmico. Posteriormente foi realizado um levantamento do quantitativo de docentes da disciplina Química que estão em atividade, e de todas as turmas de ensino técnico integrado ao médio do IFMA campus Caxias que tinham aula da disciplina em questão.

Foram escolhidas três turmas de ensino médio, compreendendo duas de $1^{\circ}$ ano e outra de $3^{\circ}$, o que representou $25 \%$ do total de alunos. Quanto aos docentes, o quadro foi composto por sete profissionais que ministram a disciplina Química, dos quais cinco que atuavam efetivamente, foram escolhidos para participarem da pesquisa.

Em seguida, foram coletadas informações para a execução da pesquisa quanto ao ensino e aprendizagem da disciplina supracitada, por meio da aplicação de dois questionários semiestruturados e distintos entre si. Foram aplicados entre os docentes e alunos na forma impressa e via formulário eletrônico. Cabe destacar que a pesquisa foi realizada no segundo semestre de 2019, antes da pandemia mundial da Covid-19.

Para coleta de dados, foi aplicado o primeiro questionário após a aula ministrada pelo professor sobre os conteúdos: reações de hidrocarbonetos e funções inorgânicas em duas turmas de primeiro ano e uma de terceiro, ambas do ensino médio. Em seguida, os cordéis, sobre os conteúdos supramencionados, foram apresentados aos alunos por meio de projeções em slides e os alunos foram convidados a fazerem a leitura e declamação dos cordéis. Por fim, foi aplicado um segundo questionário com os alunos das turmas participantes após a atividade, composto por questões fechadas, objetivando avaliar a eficácia da utilização dos cordéis na aprendizagem dos assuntos trabalhados pelo professor.

Ao final, os dados obtidos foram analisados e tabulados com o auxílio do programa Microsoft Excel - versão 2016, e gerados gráficos que permitiram uma melhor visualização e posterior análise e discussão dos resultados. 


\section{Resultados e Discussão}

Os resultados a seguir foram obtidos da aplicação dos questionários, dos quais dois foram aplicados com alunos do ensino técnico integrado ao médio e um com docentes de Química. Por meio dessa técnica buscou-se investigar as dificuldades no que diz respeito ao ensino e aprendizagem, e ainda, se a utilização da literatura de cordel pode ser eficaz como recurso facilitador do processo educacional.

Gráfico 1 - Idade e gênero dos professores participantes da pesquisa.

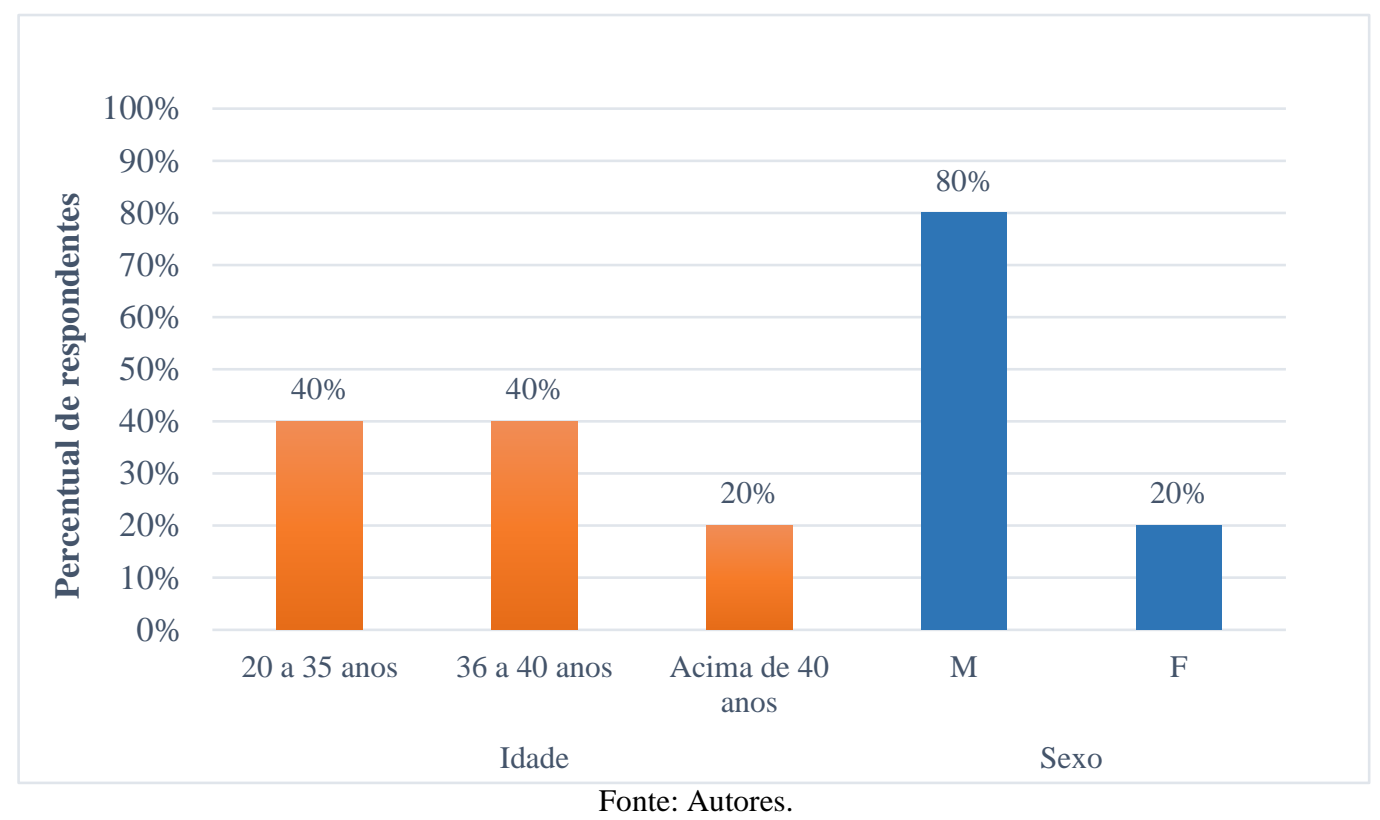

O Gráfico 1, que esboça o perfil dos docentes, mostra que 40\% têm entre 20 e 35 anos, $40 \%$ têm entre 36 e 40 anos e $20 \%$ têm mais de 40 anos de idade. Ainda de acordo com o Gráfico 1, a maioria dos docentes são do sexo masculino, o que representou $80 \%$ da amostra e $20 \%$ são do sexo feminino.

Gráfico 2 - Nível de conhecimento dos professores sobre a metodologia ativa aplicada ao ensino de Química.

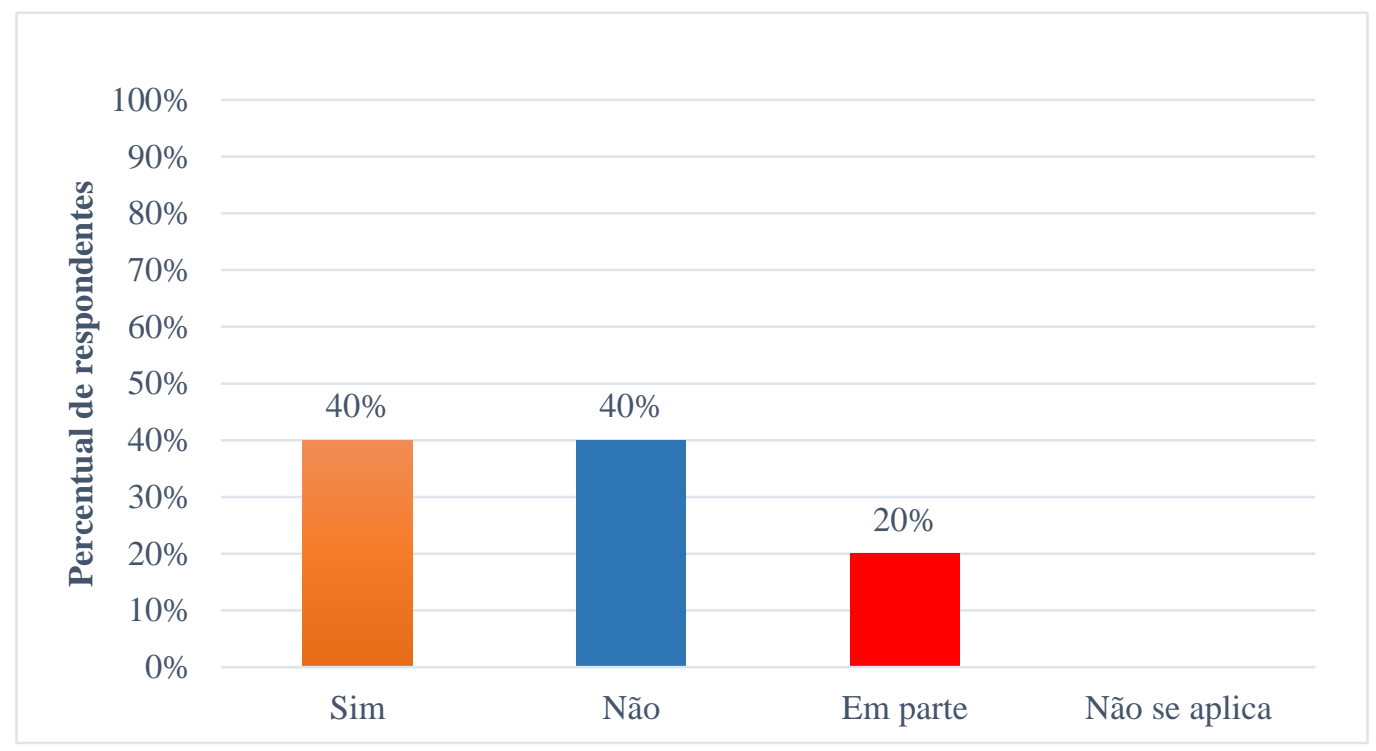

Fonte: Autores. 
Analisando a questão, a qual indaga se os professores conhecem a aplicação da literatura de cordel como metodologia ativa nas aulas de Química, verifica-se que pouco têm conhecimento acerca do uso do gênero textual no ensino da disciplina. Como apresentado no gráfico, $40 \%$ dos respondentes afirmam conhecer a aplicação dessa metodologia no ensino da disciplina em questão, enquanto $40 \%$ não conhecem e $20 \%$ conhecem em parte.

Haja vista que os saberes populares nem sempre estão incluídos na sala de aula, e não sendo conhecidos não podem ser explorados. É necessário a compreensão essa ferramenta possui um caráter altamente didático, uma vez que leva os alunos a desenvolverem importantes habilidades, como a leitura, como exemplifica Bonfim et al., (2016):

[...] o ato de ler não é uma atividade tão simples, não se pode fazer uma leitura simplesmente por fazer, é necessário estabelecer sentido e objetivo, bem como promover em sala de aula atividades de compreensão e interpretação das temáticas.

Assim, ressalta-se a importância e a necessidade do ato de ler, como desenvolver boa leitura e escrita, a capacidade de compreensão de texto e interpretação de conteúdos que se intersectam com meio em que vivemos. A aquisição maior de informações pela dinâmica dos versos de cordel, além dos fatores citados na literatura, o elege para ser utilizado nas escolas como estratégia significativa de ensino-aprendizagem, processo descrito por Moreira (2010):

Aprendizagem significativa é aquela em que ideias expressas simbolicamente interagem de maneira substantiva e nãoarbitrária com aquilo que o aprendiz já sabe. Substantiva quer dizer não-literal, não ao pé-da-letra, e não-arbitrária significa que a interação não é com qualquer ideia prévia, mas sim com algum conhecimento especificamente relevante já existente na estrutura cognitiva do sujeito que aprende.

Portanto, a aprendizagem significativa ocorre quando o indivíduo consegue assimilar as informações a partir da relação existente entre o que é adquirido, novas aprendizagens e aquilo que já havia em sua estrutura cognitiva, ou seja, o seu conhecimento prévio. Dessa forma, torna-se mais fácil aprender, pois passa-se a ter um sentido no processo.

Gráfico 3 - Avaliação dos professores quanto a importância do uso do cordel nas aulas de Química.

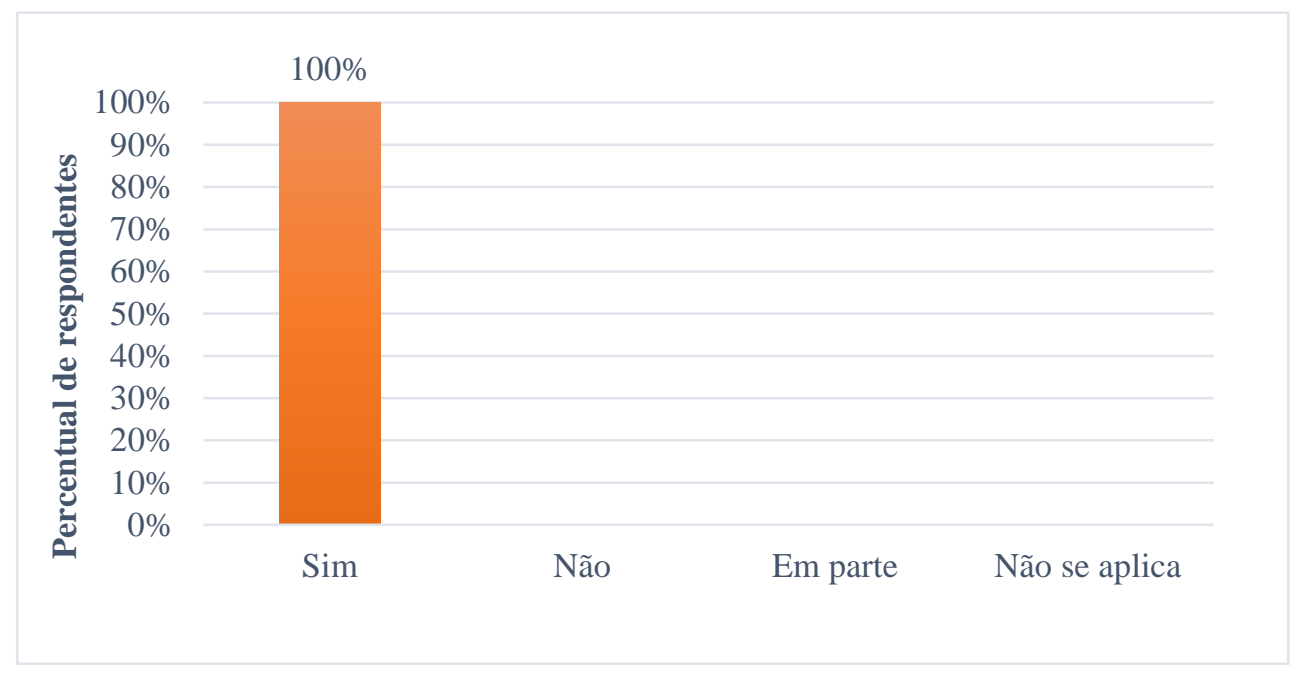

Fonte: Autores.

Os professores se mostraram receptivos quanto a utilização desse recurso didático-textual como alternativa para incremento de ensino-aprendizagem, como evidencia o gráfico. Todos eles, o que corresponde $100 \%$ do total de respondentes, afirmaram que consideram sim, importante o uso do gênero popular cordel nas aulas. 
Diversos autores vêm mostrando em seus estudos, a importância da inserção da literatura de cordel na escola como meio educativo, como explica Barbosa (2014, p. 37):

A versatilidade que a literatura de cordel oferece, permite aos professores que trabalhem a transversalidade em sala auxiliando no desenvolvimento das competências da leitura, independente do componente curricular que trabalhem, pois, a literatura de cordel aborda os mais diversos temas, sendo um grande parceiro para o professor usar na sala de aula, dependendo apenas de planejamento para facilitar a orientação do conhecimento que será repassado aos alunos.

Portanto, entende-se que esse gênero textual pode subsidiar o trabalho docente na sala de aula, de modo que essa literatura não possui padrões estéticos que exija grandes esforços dos alunos, e sim simplicidade, além de conversar com diversas áreas e temáticas, seja de cunho escolar ou não.

Gráfico 4 - Opinião dos professores quanto a necessidade de formação continuada docente.

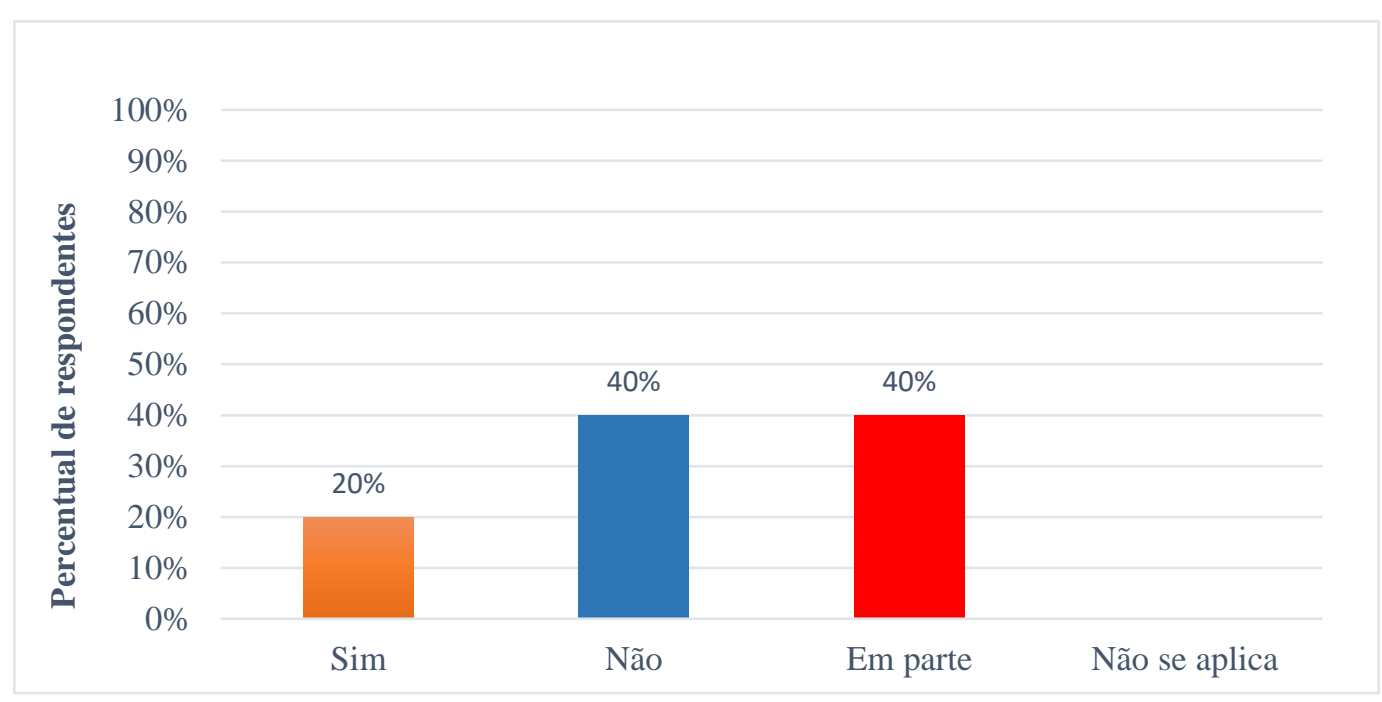

Fonte: Autores.

Ao serem questionados sobre a necessidade de capacitação como formação continuada docente acerca da temática supracitada, observou-se a relevância de tal apontada pelos professores, em que $20 \%$ responderam que considera sim necessária, $40 \%$ responderam não e $40 \%$ responderam que há necessidade em parte.

Em suma, diante de inúmeros desafios no ensino, há certa preocupação por parte dos professores em buscar meios que colaborem para o sucesso da relação mútua de discente e docente, e minimizem as dificuldades do processo de educação, conforme se pode observar nos resultados do gráfico. Os dados dizem respeito a relevância da temática apontada pelos docentes, que reafirmam a necessidade da busca de alternativas para melhorar o processo de educação, como reforça Maia (2010):

A capacitação dos docentes é essencial para que ocorra efetivamente alguma inovação na sala de aula. O que normalmente se observa nas escolas brasileiras é que o foco dessa capacitação se limita ao desenvolvimento das habilidades do professor no uso do computador, em detrimento do entendimento das possibilidades que possam ser criadas por meio da interação, da comunicação e da troca de informações entre todos os participantes.

A literatura, portanto, destaca a riqueza que pode haver na diversificação de estratégias pedagógicas. Contudo, ainda há resistência ou falta de conhecimentos que dificultam esse processo. Por isso, a importância de investimento na formação inicial e continuada, como uma preparação para se trabalhar de diferentes formas com os alunos e qualificar-se, para além da formação específica, como corrobora Rodrigues et al., (2017): 
[...] o professor necessita ter ciência de que o seu saber não é totalizado e que os alunos trazem para a sala de aula saberes prévios. O que o professor precisa é saber que em sua prática é necessário explorar a bagagem do seu alunado, pois eles têm conhecimentos que precisam apenas ser aperfeiçoado. Se propondo e se flexibilizando para modificar suas práticas metodológicas.

A perspectiva formativa de avaliar baseada na atuação do professor enquanto facilitador do processo de educação é de fundamental importância para que este não se limite a modelos estabelecidos de ensino que se concentre em repassar teorias científicas, sem uma aplicação prática e instigativa.

Então, os autores colocam a formação do professor como meio de prepara-lo para utilizar métodos e estratégias para colaborar com os alunos, que possuem conhecimentos distintos e formas distintas de aprender. Esse processo de adaptação do professor ao aluno depende da busca de conhecimentos e desejo de transformação, para que conduza os alunos ao saber fazer.

Gráfico 5 - Dificuldades no trabalho docente quanto ao ensino.



Fonte: Autores.

Foi solicitado aos professores que descrevessem as suas dificuldades em relação ao ensino da disciplina Química, caso houvesse alguma. Como descrito no gráfico acima, $20 \%$ afirmam que possui dificuldades, $40 \%$ afirmam que não possuem e $40 \%$ possuem em parte. Apenas $20 \%$ dos respondentes apresentaram explicações para suas respostas. Cujas dificuldades mencionadas foram cálculos químicos.

A partir das dificuldades relatadas pelos professores quanto ao ensino, podemos fazer a seguinte reflexão, baseada no desafio da aprendizagem em matemática:

Os professores de Matemática têm passado por momentos angustiantes quando se refere às questões de aprendizagem, por ser uma área que trata da complexidade dos números, os problemas de ensino-aprendizagem nesta área são gritantes tanto nas aulas teóricas quanto nas aulas práticas (Santos, 2020, p.14).

Logo, a matemática é percebida como uma disciplina de alta complexidade, podendo-se fazer um comparativo com as demais ciências exatas, considerando às equações e fórmulas que apresentam, sua função normativa, o que dificulta o acompanhamento do raciocínio das aulas pelos alunos, e não contribui para levar estes a verem o sentido de aplicar seus conhecimentos na prática. 
Outro fator citado foi leitura e interpretação. Contudo, tais habilidades, precisam ser trabalhadas para não afastar os indivíduos daquilo que lhe é imprescindível, a leitura e compreensão, logo, a literatura de cordel pode satisfazer essa necessidade.

Gráfico 6 - Quantidade de professores que buscam informações sobre metodologias alternativas de ensino.

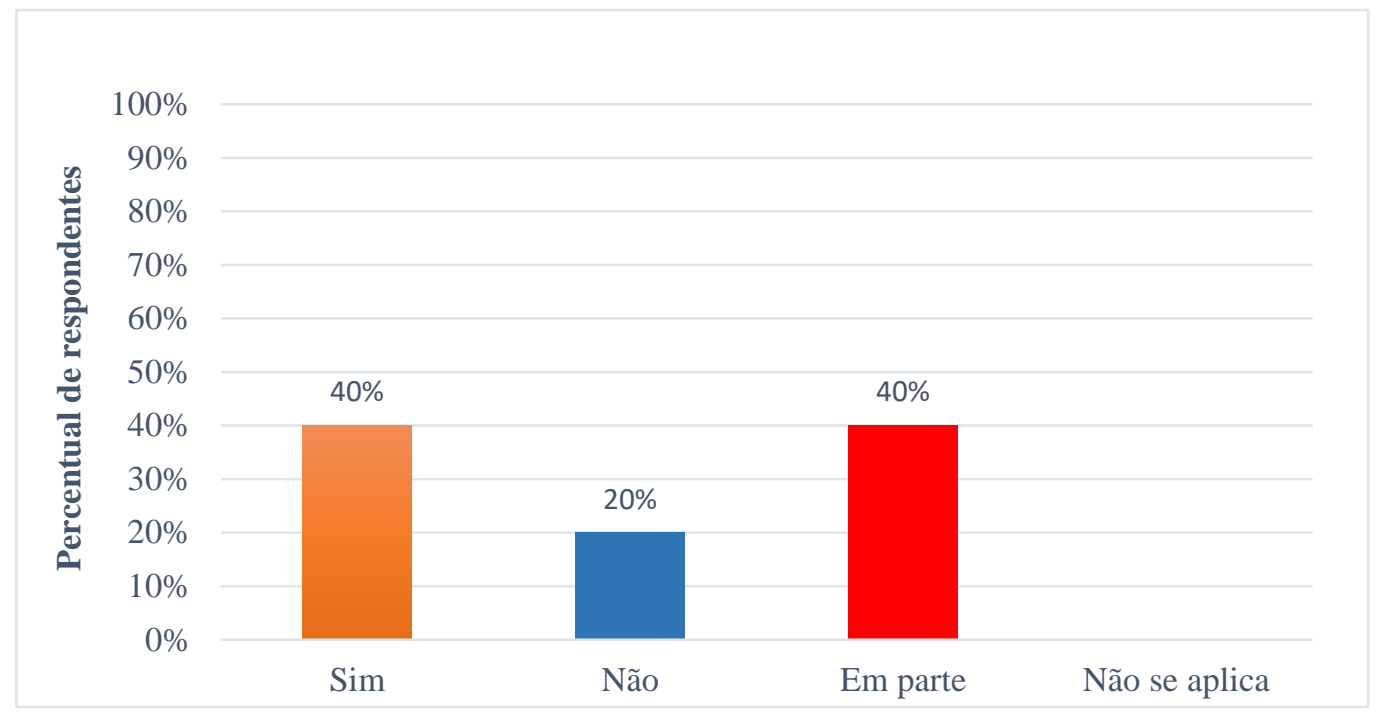

Fonte: Autores.

O gráfico acima mostra as respostas relacionadas ao hábito de leitura dos docentes, seja de livros, revistas ou artigos, sobre metodologias alternativas de ensino. Observando os dados, tem-se que 40\% dos docentes buscam atualizar-se, e, portanto, leem sobre o assunto, $20 \%$ não leem nada a respeito e $40 \%$ leem em parte.

Estes dados são importantes por que remetem à discussão de que a ciência, em seus diversos aspectos, requer constante atualização de conhecimentos para acompanhar a aprendizagem dos alunos. É inegável a necessidade de os educadores se inteirar constantemente sobre metodologias de ensino e aprendizagem, para também renovar sua prática pedagógica. Segundo Berbel (2011):

O engajamento do aluno em relação a novas aprendizagens, pela compreensão, pela escolha e pelo interesse, é condição essencial para ampliar suas possibilidades de exercitar a liberdade e a autonomia na tomada de decisões em diferentes momentos do processo que vivencia, preparando-se para o exercício profissional futuro. Para isso, deverá contar com uma postura pedagógica de seus professores com características diferenciadas daquelas de controle.

Todavia, é provável que os alunos se sintam engajados no processo educacional a partir da iniciativa e atitudes dos professores de oportunizar participações em diferentes atividades e processos significativos e flexíveis. 
Gráfico 7 - Faixas etárias e gênero dos alunos participantes da pesquisa.



Fonte: Autores.

No gráfico acima, foram agrupados os dados idade e sexo dos alunos. Vemos que o grupo é bem misto, o qual a maioria dos alunos são do sexo feminino (66\%) e 34\% são do sexo masculino. A idade dos participantes variou bastante, temos alunos entre 14 e $18(69 \%)$, entre 19 e 30 anos (15\%), entre 31 e 40 (12\%), entre 41 e $45(3 \%)$, acima de 70 anos (1\%).

Gráfico 8 - Dificuldades dos alunos relativas à aprendizagem da disciplina.

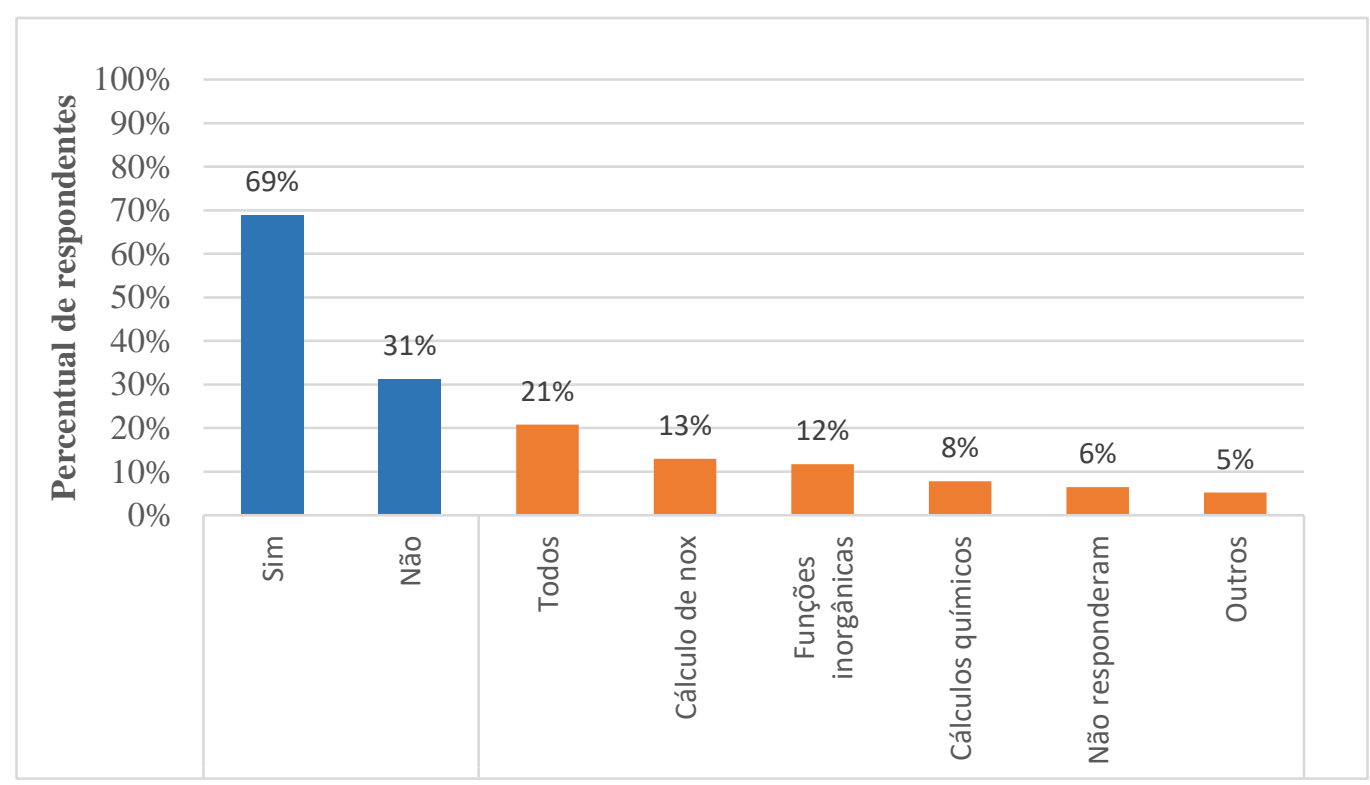

Fonte: Autores.

No gráfico, observa-se o percentual significativo o percentual de alunos que afirmam ter dificuldades com a disciplina Química (69\%), e é considerável o número de alunos que disseram não ter dificuldades em relação a disciplina (31\%), o que é absolutamente satisfatório.

Foi solicitado ainda, que aos alunos que especificassem em quais conteúdos de química no presente semestre possuíam dificuldades. O resultado foi o seguinte: Todos os conteúdos (20\%), cálculo de nox (13\%), funções inorgânicas (12\%), cálculos químicos $(8 \%)$, outros (5\%), não responderam (6\%). 
A questão das dificuldades dos alunos relacionadas à Química apresenta dados que nos remetem às discussões já conhecidas baseadas em pesquisas e seus sujeitos, intervenções e estudos da literatura, que a Química é complexa, é desinteressante. Isto colabora para o aluno não querer aprendê-la e não perceber que há uma estreita relação dela com o nosso cotidiano.

Em relação a complexidade da disciplina estudada, o que se torna um entrave para o êxito no processo de educação, visto que acentua as dificuldades de aprendizagem, Albergaria (2015) explica, neste sentido que:

A Química cada vez mais se enquadra entre as disciplinas consideradas difíceis pelos alunos do ensino médio. A compreensão e interação dos alunos nas aulas de química têm sido cada vez mais complicadas, o que acaba dificultando o processo de ensino-aprendizagem.

Entretanto, apesar das dificuldades com a ciência, boa parte dos alunos relataram ter facilidade com os conteúdos, o que é plausível, pois decorre que esteja havendo, de fato, uma aprendizagem, na qual os alunos entendem a importância e os motivos de aprenderem e aplicarem o conhecimento na vida escolar e social.

Em contrapartida, deve-se refletir acerca da estratégia que ensino que está sendo utilizada, uma vez que existem muitos caminhos que podem conduzir à aprendizagem significativa dos conteúdos, que contemple as diferentes formas de aprender dos alunos, tornando esse processo prazeroso e não obrigatório, condição apontada por Costa (2015):

De fato, para que uma aprendizagem ocorra, ela deve ser significativa, o que exige que seja vista como a compreensão de significados, relacionando-se às experiências anteriores e vivências pessoais dos alunos, permitindo a formulação de problemas de algum modo desafiantes que incentivem o aprender mais, o estabelecimento de diferentes tipos de relações entre fatos, objetos, acontecimentos, noções e conceitos, desencadeando modificações de comportamentos e contribuindo para a utilização do que é aprendido em diferentes situações.

Dessa forma, os alunos poderão construir sua autonomia dentro do processo de desenvolvimento de habilidades e compertências, baseando-se em suas experiências e colaboração dos professores no sentido de conduzi-los à aprendizagem efetiva.

Gráfico 9 - Principais causas das dificuldades em Química apontadas pelos alunos.

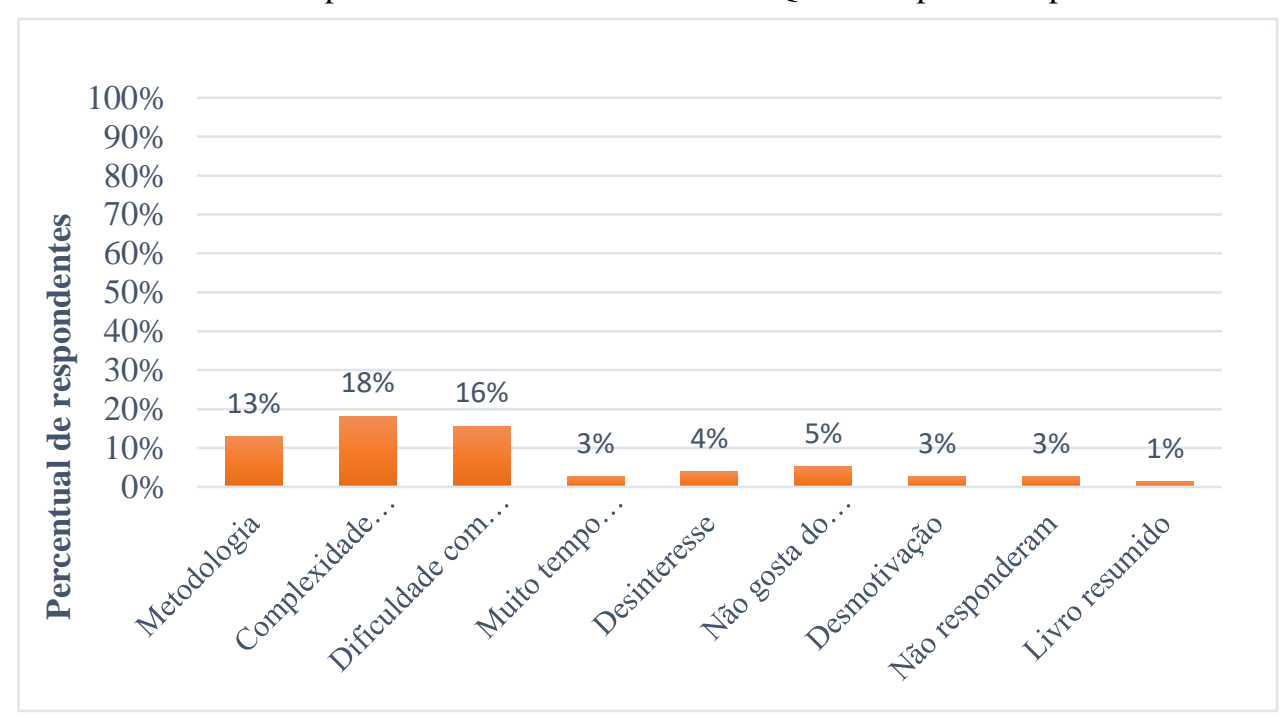

Fonte: Autores.

Estão apontados, no gráfico acima, alguns fatores que dificultam, segundo os alunos, a aprendizagem referente à Química. Percebe-se que $18 \%$ dos respondentes retratam a complexidade da disciplina como principal fator causador de dificuldades, ficando 
à frente de $16 \%$ relativos à dificuldade com cálculos. O outro fator mais evidenciado no gráfico, está relacionado à metodologia utilizada pelo professor $(13 \%)$.

Os demais motivos apontados pelos discentes consistiram em: muito tempo sem estudar (3\%), desinteresse (4\%), não gostam do assunto/disciplina (5\%), desmotivação (3\%), livro resumido (1\%) e 3\% não responderam. Em relação a estes dados, um ponto que deve ser considerado é que os alunos que responderam que há muito não estudam, são os estudantes de turma de EJA e que ficaram prejudicados por esse tempo fora da escola.

Outro fator que está mais evidenciado na desrição do gráfico, é a metodologia utilizada pelo professor (13\%). É importante destacar que a metodologia proposta seja compreensível aos alunos, revelando-se instigante, atraente e dinâmica. Este é um ponto muito discutido no meio educacional e acadêmico, sendo relevante pelo fato de que o ensino deve acompanhar o ritmo das mudanças no processo de conhecimento, já que a tecnologia informacional, principalmente, vem revolucionando a recepção das informações e consequentemente, as formas de aprender. Neste sentido, Silva (2014, p.19) argumeta:

Os professores precisam ser dinâmicos, ativos e voltados para a compreensão do universo dos alunos. A metodologia utilizada deve envolvê-los no processo, tornando-o participante. Uma das variáveis que induz a evasão são práticas docentes em que os alunos se mantêm passivos.

O autor menciona algo primordial para o êxito do ensino no ambiente escolar, a dinamicidade das aulas, objetivando inserir e envolver os alunos de forma participativa, assim, fortalecer-se não só a motivação, mas a busca pelo conhecimento autônomo por parte dos alunos.

Um ponto preocupante é o fato de os alunos não terem interesse, não possuírem motivação para os estudos e não conseguirem se apropriar das ferramentas disponibilizadas para eles consultarem sempre que necessário, no caso, o livro didático, e que em conjunto representam um agravante na aprendizagem e na relação dos alunos com a disciplina.

Gráfico 10 - Opinião dos alunos acerca da importância da utilização do cordel nas aulas

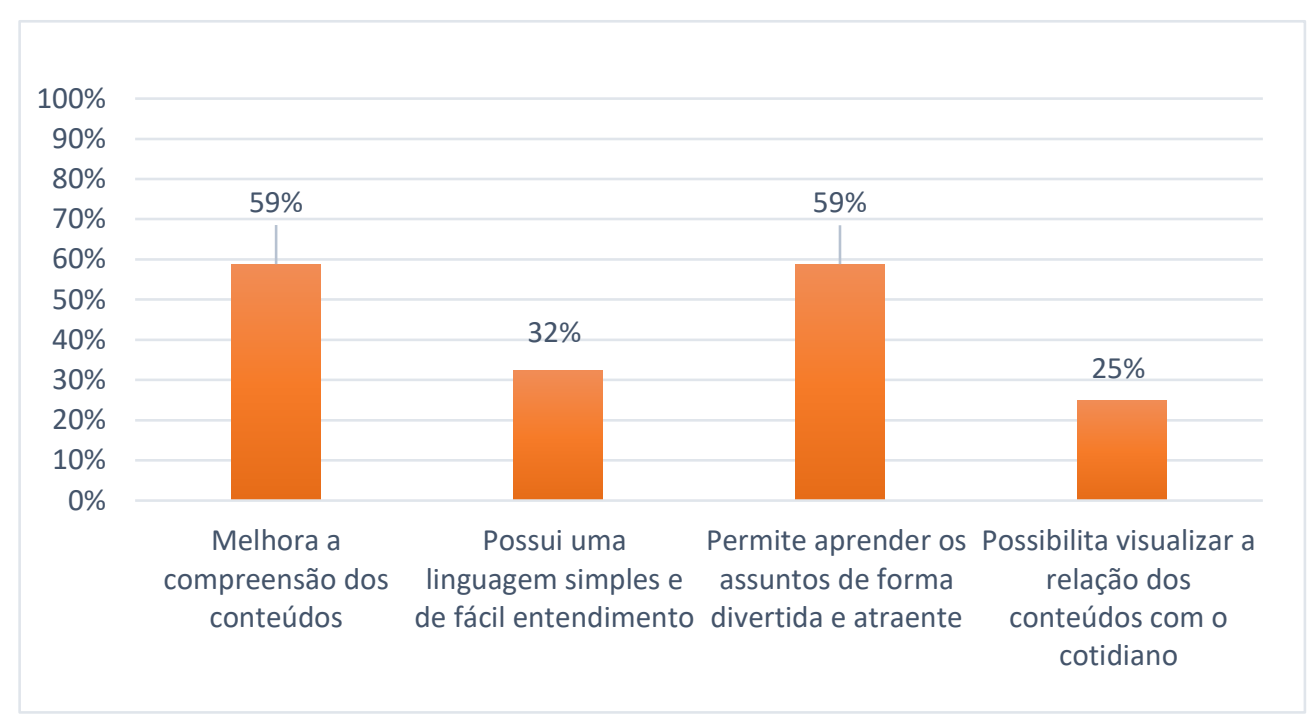

Fonte: Autores.

O Gráfico 10 expressa a visão dos alunos de como a literatura de cordel pode colaborar com o ensino de Química, a partir da experiência em sala. Após a demonstração dos conteúdos em forma de rimas, eles chegaram à conclusão, que o recurso 
melhora a compreensão dos conteúdos (59\%), possui linguagem simples e de fácil entendimento (32\%), a aprendizagem se torna divertida e atraente $(59 \%)$ e permite a visualização da relação dos conteúdos com o cotidiano (25\%).

Os dados apresentados estão baseados nos benefícios que o cordel pode proporcionar se inseridos na educação. Consonante a este pensamento, Cruz $(2015$, p.3) aponta:

O uso da literatura cordelista como instrumento educativo, chama atenção pela forma simples de observação do autor transcrita nos folhetins. [...] Deste modo, a literatura popular é fonte de multiplicidade de significados da realidade. Segundo estudiosos, dentro de uma concepção intertextualizada, o cordel pode ser incentivador do aluno no gosto pela leitura, visto que ele é fonte de palavras lúdicas, temas abrangentes e um poder de síntese peculiar e incomum, tendo possibilidade de ser suporte pedagógico na atualidade.

Observa-se que a transposição da realidade é umas das características bem marcantes do cordel, e sobretudo, seu potencial educativo pautado na linguagem simples e de fácil entendimento, na contextualização, na forma dinâmica em que é apresentado e construído. Todos esses fatores o tornam um recurso pedagógico de grande valor para a educação.

Gráfico 11 - Opinião dos alunos sobre a qualidade da aplicação do cordel.

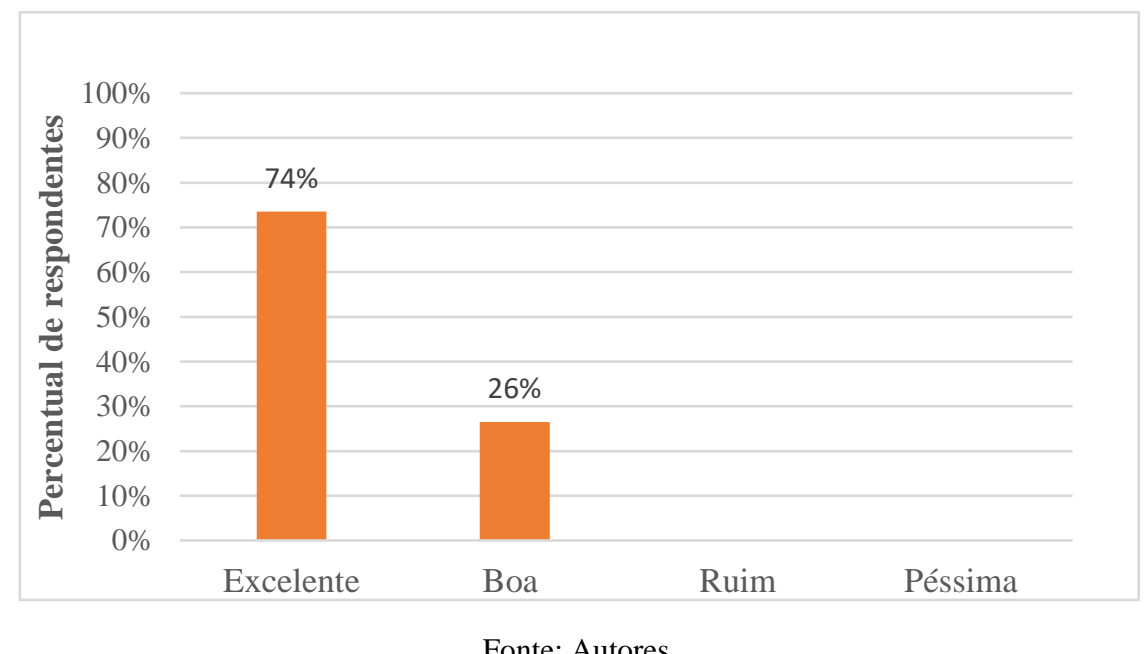

Fonte: Autores.

Os dados da questão abordada no segundo questionário, representados no gráfico acima, referente a aplicação do cordel como atividade mediadora do ensino-aprendizagem, revelam que 74\% dos alunos mostraram uma boa aceitação do uso do cordel nas aulas de Química. Para eles a atividade, contribuiu, principalmente com a dinâmica, proveniente da leitura do conteúdo. Um percentual de $26 \%$ dos estudantes também considerou a atividade boa, que reafirma o argumento citado anteriormente. Neste sentido, Medeiros et al., (2016) aponta que:

Através deste gênero literário objetivos educacionais podem ser atingidos, visto que na literatura de cordel, as características que mais se destacam, como as rimas e a linguagem coloquial, respectivamente, situa o leitor acerca do conteúdo explanado, por meio da incrível faceta de articular o popular ao científico.

Ou seja, as peculiaridades da literatura de cordel que a tornam simples e de fácil entendimento, representa a essência didático pedagógica para diversos contextos, que pode potencializar a busca de objetivos educacionais. 
Gráfico 12 - Opinião dos alunos acerca da contribuição do cordel como meio facilitador de aprendizagem.

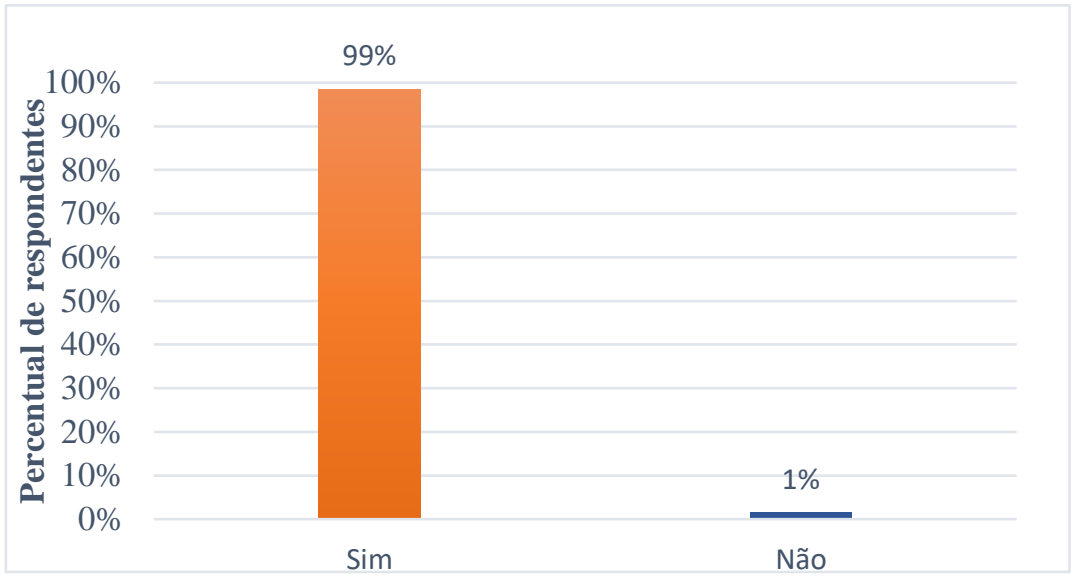

Fonte: Autores.

Com base no gráfico, verifica-se a satisfação dos alunos a respeito do envolvimento do cordel com a Química, pois 99\% declararam que conseguiram assimilar os conteúdos com maior facilidade, o que reforça a importância do uso do cordel nas aulas, e apenas $1 \%$ disse que não conseguiram aprender de maneira eficaz a partir do emprego da metodologia.

Nesta perspectiva de colaborar com a compreensão dos conteúdos, é necessário diligência dos docentes, pois a aplicação pura do cordel nas aulas não é favorável à aprendizagem. Embora a leitura do cordel, como toda leitura deve ter um objetivo, este é uma ferramenta auxiliar do ensino, que deve complementar as aulas ministradas pelos professores, não sendo um fim em si mesma.

Gráfico 13 - Identificação dos alunos com a metodologia proposta em sala.



Fonte: Autores.

Também buscou-se saber se os alunos gostariam de trabalhar com essa metodologia de ensino, $99 \%$ deles não só conseguiram melhorar sua compreensão dos conteúdos, como gostariam de ter um contato maior com essa ferramenta de ensinoaprendizagem, enquanto $1 \%$ não se mostrou satisfeita e não deseja vivenciar essa metodologia. Tal fato aponta novamente para a necessidade de atividades desse cunho para serem trabalhadas na sala de aula: 
Desta forma, o cordel pode ser trabalhado em mais de uma disciplina ao mesmo tempo, configurando uma proposta interdisciplinar inovadora, que auxilia extrair habilidades e aflorar a criatividade dos alunos ao passo que promove a realização de atividades que eles prezem, como desenhar, cantar, tocar, encenar, entre outras (Pereira, 2018).

Logo, constatou-se que o gênero popular cordel constitui-se de uma série de vantagens se utilizado nas aulas, bem como no ensino de Química, considerando o seu caráter criativo, interdisciplinar, estimulador, que se encaixa como meio inovador e rico de possibilidades e estratégias pedagógicas.

\section{Considerações Finais}

Os resultados da pesquisa demonstraram a importância da utilização da literatura de cordel nas aulas de Química, uma vez que pode contribuir no sentido de dirimir as dificuldades do ensino e aprendizagem e ao mesmo tempo, potencializar os conhecimentos abordados na sala de aula.

As dificuldades no que diz respeito ao ensino e aprendizagem de Química são comumente relatadas por ambas as partes, como a dificuldade com cálculos, metodologia empregada nas aulas, o desinteresse causado pela complexidade da disciplina, dentre outros. Contudo, as possibilidades didáticas do gênero cordel oferecem outro viés para o ensino e aprendizagem, baseando-se em sua simplicidade, poder de incremento e criatividade, de modo que os estudantes vejam o ensino sob outra perspectiva que poss a mantê-los interessados e estimulados a aprenderem e desenvolverem habilidades e competências estudantis para progredir nos estudos.

Um dos aspectos que se destacaram ao longo do estudo consistiu no envolvimento de todos os participantes, reafirmando a literatura de cordel como metodologia ativa eficaz no ensino e aprendizagem da química, impulsionando a literatura no ambiente escolar, e fomentando o desenvolvimento da capacidade crítica e da oralidade dos alunos.

Como limitação do estudo, declara-se que não foi possível realizar a oficina de confecção de cordéis por conta da ausência de disponibilidade de carga horária de aulas dos docentes. Entende-se a importância de os alunos produzirem seus próprios cordéis, de modo a vivenciarem a experiência da escrita a partir de suas perspectivas e realidades.

Como sugestão de trabalhos futuros acerca deste tema, propõem-se que o gênero textual literatura de cordel como metodologia ativa no processo ensino aprendizagem seja pesquisado nas licenciaturas de Química, no sentido de avaliar a eficácia da utilização do gênero em questão pelos docentes na ministração das aulas. Considerando-se o fato que os alunos das licenciaturas poderão se tornar professores, atuando em sala de aula, eles tenderão a replicar o uso do gênero textual supramencionado com seus alunos, de modo a corroborar com a otimização da aprendizagem.

Ao inserir o gênero textual literatura de cordel como proposta didático-pedagógica nas atividades de química, foi possível mediar os conhecimentos prévios dos alunos com os assuntos da disciplina, efetivando a aprendizagem por meio da aproximação dos alunos à cultura popular. Nessa perspectiva, é possível pensar estratégias que desenvolvam no aluno o interesse pela leitura e que façam com que ele se sinta motivado a aprender, de modo que perceba as aulas como algo prazeroso e não obrigatório.

Diante do exposto, entende-se que os resultados demonstraram a contribuição do gênero popular literatura de cordel para a formação do conhecimento científico. Diante dos aspectos atribuídos à atividade pelos alunos, a utilização do cordel como potencializadora do ensino e aprendizagem representa uma metodologia didática que atravessa os limites curriculares promovendo a interdisciplinaridade dos conteúdos.

\section{Referências}

Albergaria, M. B. (2015). Caracterização das principais dificuldades de aprendizagem em química de alunos da $1^{\circ}$ série do ensino médio. Trabalho de conclusão de curso (Licenciatura em Ciências Naturais) - Faculdade UnB Planaltina, Universidade de Brasília UnB, Planaltina. https://bdm.unb.br/bitstream/10483/13838/1/2015_MayaraBezerradeAlbergaria.pdf. 
Andrade, T. O. (2012) A leitura na escola e a formação do leitor no Ensino Fundamental I. Revista Científica Indexada Linkania Júnior, v.2, n.2 - ISSN: 22366652. http://linkania.org/junior/article/download/35/36.

Barbosa, A. M. (2014) O uso da literatura de cordel no ensino médio. Monografia (Especialização Em Práticas Pedagógicas Interdisciplinares) - Universidade Estadual Da Paraíba, João PessoA - PB. http://dspace.bc.uepb.edu.br/jspui/handle/123456789/19894.

Berbel, N. A. N. (2011) As metodologias ativas e a promoção da autonomia de estudantes. Semina: Ciências Sociais e Humanas, 32(1), 25-40. http://www.uel.br/revistas/uel/index.php/seminasoc/article/view/10326/10999.

Bomfim et al. (2016) O gênero cordel como objeto de ensino. Anais da V Semana de Integração Inhumas: UEG, p. 540-549. https://www.anais.ueg.br/index.php/semintegracao/article/view/6127.

Carreiro et al. (2012) A importância do uso da literatura do cordel como facilitador do ensino- aprendizagem da química orgânica no ensino médio. In: XVI encontro nacional de ensino de química (XVI ENEQ); X Encontro de Educação Química da Bahia (X EDUQUI), Salvador, BA. https://portalseer.ufba.br/index.php/anaiseneq2012/article/view/7933/5639.

Costa, A. (2015) A Importância Da Aprendizagem Significativa Na Formação Profissional. https://www.rhportal.com.br/artigos-rh/a-importncia-daaprendizagem-significativa-na-formao-profissional/

Cruz, D. A. C. S. (2015) Educação, mídia e literatura de cordel: propostas para uma nova pedagogia na contemporaneidade. X Encontro Regional Nordeste de História Oral. Salvador, BA. http://www.historiaoral.org.br/resources/anais/11/1439166818.pdf.

Gil, A. C. G. (2010) Como elaborar projetos de pesquisa. (4a ed.), Atlas.

Lakatos, E. M. \& Marconi, M. A. (2017) Fundamentos de metodologia científica. (7a ed.), Atlas.

Lima, S. T. (2013) Os PCN e as potencialidades didático-pedagógicas do cordel. Acta Scientiarum. 35(1), 133-139. http://www.repositorio.ufc.br/ bitstream/riufc/19897/1/2013_art_stlima.pdf.

Maia, M. C. (2010) Entendendo a necessidade de renovação no processo de ensino e aprendizagem. RAE-eletrônica, 9(1), https://rae.fgv.br/sites/rae.fgv.br/files/artigos/10.1590_S1676-56482010000100010.pdf.

Medeiros et al. (2016) Literatura de cordel na prática educativa do PIBID. Carpe Diem: Revista Cultural e Científica do UNIFACEX. 14(1). 2237 - 8685. https://periodicos.unifacex.com.br/Revista/article/view/696.

Moreira, M. A. (2010) O que é afinal aprendizagem significativa? Instituto de Física, Universidade Federal do Mato Grosso, Cuiabá, MT, p.2. http://moreira.if.ufrgs.br/oqueeafinal.pdf.

Pereira, M. G. (2018) Ciência em cordel: uma perspectiva literária para o ensino de evolução. Trabalho de conclusão de curso (Licenciatura em Ciências Biológicas) - Centro acadêmico de Vitória, Universidade Federal de Pernambuco, Vitória De Santo Antão. https://attena.ufpe.br/bitstream/123456789/28930/1/Pereira\%2C\%20Maria \%20Gislaine.pdf.

Prodanov, C. C. (2013) Metodologia do trabalho científico: métodos e técnicas da pesquisa e do trabalho acadêmico. (2a ed.), Feevale.

Rodrigues et al. (2017) A importância da formação continuada de professores da educação básica: a arte de ensinar e o fazer cotidiano. Saberes docentes em ação, 3(1), 2525-4227.

Santos, E. et al. (2019) Reflexões acerca das potencialidades didáticas da literatura de cordel para o ensino de ciências. Revista de Educação, Ciências e Matemática. 9(2), 2238-2380. http://publicacoes.unigranrio.edu.br/index.php/recm/article/download/4976/305.

Santos, J. B. (2020) A matemática: dificuldade no processo de ensino aprendizagem no ensino médio do colégio Estadual Dr. Jessé fontes. http://brasilesco.la/m14494.

Severino, A. J. (2017) Metodologia do trabalho científico. (2a ed.), Cortez.

Silva, G .B. (2014) O papel da motivação para a aprendizagem escolar. Monografia (Especialização fundamentos da educação) - Universidade Estadual da Paraíba, João Pessoa, PB. http://dspace.bc.uepb.edu.br/jspui/bitstream/123456789/9644/1/PDF\%20-\%20Geruza\%20Barbosa\%20da\%20Silva.pdf. 